\title{
Failure Characteristics on ADNAN (Malaysian Armoured-Vehicle) Track Shoe and its Improvements
}

\author{
Muhamad Hellmy Hussin, NurAzida CheLah, Shamsul AkmarAbd. Aziz
}

\begin{abstract}
Armoured military vehicle is designed to withstand the stresses impact from bullets, missiles or any explosive shells. It is applied to the vehicle in order to protect the personnel inside from enemy fire and also to protect from any threats other than deliberate attack. However, an issue arises when it comes for track link shoes of the armoured vehicle which already became problems to the designers and users of tracked vehicles. The track link problems usually related to the problems that already existed because of its excessive weight, excessive noise and vibrations, overheating of rubber track elements and road wheels, etc. All of these existing problems could leads to the failure of pin and bushing, chunking of the pads and breaking of the track links itself. Instead of that, today's tracks are much more expensive not only in terms of initial cost but also the replacement cost. Here, this paper reviews some of the failure cases and improvements of the armoured-vehicle itself. It also covers a real study on the failure assessment of the ADNAN (The Malaysian Armoured-Vehicle) Track Shoe.
\end{abstract}

Index Terms: military vehicle, rubber track, pin and bushing, impact stress, vibration.

\section{INTRODUCTION}

An armoured military vehicle is mainly designed for significant used by military forces. In military, this is an important vehicle which has role in all types of land and also as a transportation vehicle. Commonly, this type of vehicle usually armoured purposely to withstand the impact forces from shrapnel, bullets, missiles or any kind of explosive shells. In other words, this military vehicle is also designed to protect the personnel inside from enemy fire and also from any threats other than deliberate attack [21].

The military truck which generally weighs about 550 $600 \mathrm{kN}$ is one type of military vehicle that is purposely developed to supply and transport fuel, military needs and troops to the battlefield [18]. Different countries have their own military truck models and each of that has its own

Revised Manuscript Received on February 05, 2020.

* Correspondence Author

Muhamad Hellmy Hussin*, Fabrication \& Joining, University of Kuala Lumpur Malaysia France Institute (UNIKL MFI), Selangor, Malaysia.

NurAzida CheLah, Fabrication \& Joining, University of Kuala Lumpur Malaysia France Institute (UNIKL MFI), Selangor, Malaysia.

Shamsul AkmarAbd. Aziz, Science \& Technology Research Institute, Defence (STRIDE), Selangor, Malaysia.

(C) The Authors. Published by Blue Eyes Intelligence Engineering and Sciences Publication (BEIESP). This is an open access article under the CC BY-NC-ND license (http://creativecommons.org/licenses/by-nc-nd/4.0/) technical characteristics. The difference also includes the amount of the armour plating carried which determines their excessive weights and it is often very heavy. In general, a military truckare comprised of parts and components such as chassis, a transmission, a motor, a cabin, compartment for the placement of the load and the equipment, axles of transmission, and suspensions. Besides that, it also consist of tires, electrical, pneumatic, hydraulic, engine cooling systems and brakes [16]. In addition, Ramamurthy et al.[16] stated that this tank is capable of running at higher speeds and they are generally provided with passive suspension systems using torsion bar and shock absorbers which contribute in the attenuation of terrain vibrations.

In attempting to study and assess the potential of high performance character for combat tracked vehicles, particularly the track shoe, this paper also reviews some of the failure studies and improvements which have been made to the track link of armoured-vehicle in various countries. It is not only focusing to the Malaysian Military Army but it also includes the basic studies of the tracked-vehicle itself. It also covers a real case study on the failure assessment of the ADNAN (The Malaysian Armoured-Vehicle) Track Shoe.

\section{EXPERIMENTAL WORKS}

In this study, based on critical survey of relevant literature and focused on own experience in visualizing the cracks and flaws on the ADNAN track shoe, a failure analysis methodology is presented. Data gathering were aimed in order to locate the initiation of failures. Samples were collected and sectioned for laboratory examination. Further analysis was carried out using visual inspection to identify the defects non-destructively using DSLR Camera.

\section{RESULTS AND DISCUSSION}

\section{A. Track Link System}

Track link system of armour fighting vehicle is one of the important designed part to fit the purpose and it determines the amount of armour plating carried and excessive amounts leads to the mobility restriction. One of the major parts is continuous track or also known as tank tread or track shoe. This part is the one of the main truck system which also known as vehicle propulsion system which comprised of an arranged track plates which driven by wheels. This band of arranged plates is usually made of modular steel plates or it is also made of synthetic rubber which is reinforced with steel wires for lighter agricultural or construction vehicles. 
This continuous track usually consists of large surface area to enable truck vehicle's weight distribution and it also protects the track link from sinking. The aggressive and heavy duty behaviour of truck tread supports good traction in soft and paved surfaces. Instead of vehicle fighting truck, it also can be found on many types of large vehicles such as bulldozers, tractors and excavators. Some of its advantages of using tracked vehicles are have better mobility than pneumatic tires over rough terrain and can smoothly glide over small paved obstacles. It also has capability of crossing trenches, and less likely to get stuck in soft ground such as mud or snow ice since the weight distribution of the vehicle over a large contact area. Thus, decreasing it's ground pressure [5].

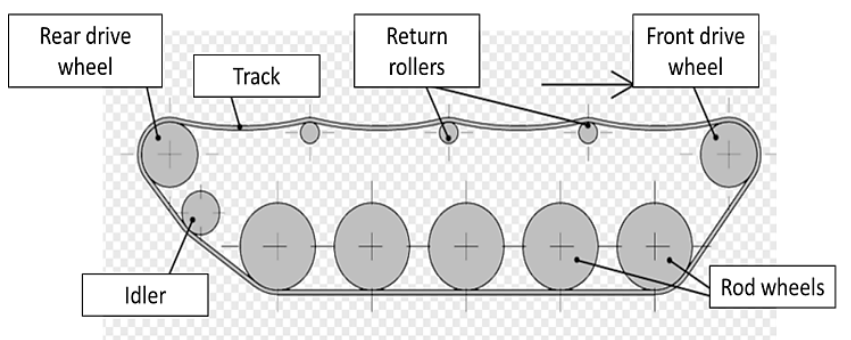

Fig. 1. Tracked suspension diagram

As indicated in Fig. 1, modern tracks are built from modular chain links. This type of chain link consists of a closed chain together with the links that are joined by a hinge. This design provides an easy and flexible that wrapped around the wheels to order to provide an endless loop. Improvement were significantly focused on the combat and support vehicle of the army in years. The objective of the improvement is to support army to move on the ground with utmost agility. As reported in 1980 by Karafiath [6], for track vehicles, the speed of turning is required for evasive tactics to be successful is often limited by the high turning resistance encountered in soft soils and by the ability of the army vehicles to develop the slewing forces which is necessary to overcome these turning resistance. Thus, from the simulation, they developed a model with turning performance characteristics such as coefficient of turning resistance, time required to make 90o turns, maximum speed at constant radius and maximum speed along sinuous path.

Lessem and Murphy [9] conducted a field test program on four tracked vehicles. This field test is aimed to determine the strength of the track and its effectiveness of ride dynamics and also develop a mathematical model. In the test, the tracked vehicles were tested and pushed over an assortment of obstacles. Comparison test were carried out for vehicle with without track installed. According to the result, they found that direct dynamic responses between these two conditions. It is clearly indicated that the track influence is definitely related with velocity. They also developed a mathematical model to provide essential features in track mechanic behavior. Besides dynamics factor, vibration is most common domination factor that can influence the fatigue and safety of the crew. Earlier studies reported that both the wheeled and tracked off-road heavy vehicles were subjected to low frequency and high amplitude vibration environment during riding [16]. This would be the causes for body discomfort, insufficient performance and physiological damage of the operators of such heavy vehicles.

One of the major issues is the extreme service environment and unpredictable peak loads that the track vehicle must survive and maintain its toughness and durability. Major catastrophic failures involving blocks, links or connectors will definitely immobilize the vehicle. In this case, materials selection used need to have important key properties such as strength, fracture toughness, ductility, fatigue strength and resistance to corrosion and wear. These factors would become a vital primary design consideration.

\section{B. Mechanical Durability of Rubber Used in Track Shoe}

In spite of its advantages, the continuous track link usually facing a hard situation even when one single segment in track link immobilizes the entire vehicle. This situation can cause the vehicle to stop and completely off their guide system where on-site repair is possibly needed. One of the conditions is jammed tracks which may become so tight and it requires special tools where repair is possible depending on the type of wheel pattern and the level of severity. In most cases, the track shoe can fail in a variety of ways principally in the rubber bushing and at the sprocket interface.

As reported by Bennink [2] the life of track chains and rubber belts is the most important factor especially in tension of the system. He also stated that guide or drive lugs usually experienced wear and tear due to side wear. Moreover, the debris ingestion also could leads to chunking problem and eventually become tear-off. These are the common problems encountered especially on rubber track failure. Meanwhile, for paver application, normal wear out of the tread is the most common problems. Importantly, it's getting worse if the asphalt was found in the inner track's surface. As a consequences, this condition will leads to a weak and thus having wear out the especially at the wheel path rubber [15].

Richard [17] wrote that one of the technique to make tracked vehicles eco-friendly, safer and definitely comfortable for the people inside them is to replace the existing rubber with the use new high-tech rubber tracks. Tracked military vehicles with metal plates tracks shows to have several inconvenient including severe vibrations which caused bad health to the tracked passenger and also to the mechanical parts of the vehicle. This could leads to more frequent breakdowns. Instead of that, fuel economy is also affected. Report from experiments conducted at Yuma Proving Grounds. Basically the test was conducted on the paved, gravel and cross-country area. The track pad failures were found on the T142 track. It shows significant tensile stresses were found on the pads due to the scrub effects over the obstacles. They found that localized loads and also large shear stresses applied during turning operations. This can also be the reason that caused tensile stresses to develop. In addition, the temperature data was taken on the surfaces of the tank pad and it showed that high temperature can be produced in track pads [8]. Thavamani et al. [19] investigated the effect of ageing on the strength and wear of natural rubber (NR), styrene-butadiene rubber (SBR), NR-SBR blends and hydrogenated nitrile rubber (HNBR) based tank track pad compounds over a range of ageing temperatures and compounds. 
The results show that HNBR compounds show a stable ageing resistance at all the ageing temperature which is 75 125 oC. The other compounds lose about $60 \%$ to $90 \%$ of their original strength indicating their unserviceability above $75{ }^{\circ} \mathrm{C}$. McKenna [12] reported on the research performed to evaluate the mechanical durability of carbon-black-filled rubbers used in track pads on United States Army tracked vehicles. A tri-blend rubber type 15TP-14AX, a natural rubber compound 15NAT-25A and the commercial rubber of unknown composition 15TP-R were selected for the study. It was found that the CSFE model approach was not applicable to any rubber compound suggested. He concluded that the failure for these rubbers depend upon the type of testing even in quasi-static test for example in creep. The results show that the ranking varies with test conditions such as temperature, test frequency etc. Mars et al. [11] studied on the fatigue life and durability of twin track pad of vehicle track pads. They found that the fatigue life falls between 103 and 107 cycles. Thermal runaway predictions for the T-158LL backer pad were also validated against test in cases where debonding of the rubber from metal core occurred $[7,11]$.

For the past 30 years, invention related to improving rubber compounds were generally related to the improvement of elastomeric components for tread pads of tracked vehicles. The focus part is endless track military vehicles with plurality of linked metal track shoes. Touchet et al. [20] reported that the invention that they worked on basically is to overcome the problems such as cutting and chipping resistance, tear and tensile strength, crack growth resistance, abrasion resistance, hysteresis and thermomechanical stability. The patented improvements made on rubber composition for tank pads which should include at least one surface portion, preferably the portion which contacts the ground is the main major problems. Sridhar et al. [18] found that the track pin which is made of steel and surrounded by rubber bush is an important component in the tracks heavy load vehicle which enables the pin to transmit torsional loads. They came out with finite element method to estimate the stresses in the rubber [4].

\section{ADNAN Malaysian Armoured Vehicle Track Shoe}

A real photo showing the track chain of ADNAN, an armoured vehicle of Malaysian Army as depicted in Fig. 2. The Malaysian variant of the AIFV (Armoured Infantry Fighting Vehicle) is called ADNAN.The name of ADNAN is given after Adnan bin Saidi, who was a Malayan Lieutenant and a hero who fought in the battle of Singapore during World War II.The ADNAN track link blocks with rubber pads are connected by means of track pins and the end connectors as shown in Figs. 3 and 4.

Fig. 4 presents a typical pin which consists of circular steel rod and the rubberised bushes. It is embedded on the steel pin with intervals between the bushes. The same procedure experienced by other armoured vehicles also applied to ADNAN where the pin is inserted into the block holes. When the insertion of pin begins, the bush was found having compression stress. As consequences, the rubber fills these intervals and was found to transforms into a full cylindrical shape. When ADNAN is in operations and manoeuvred by personnel, the relative movement between the blocks is accommodated by twisting the rubber bush. The most common failure factor is mainly dependent on the rubber

bush.

As indicated in Fig. 5, one of the parts of rubber bush was worn and torn due to the filling of rubber into the block. In Fig. 5 (a) the rubber in this bushing looks almost new. The rubber bush has failed in a relatively small area in a purely radial direction (Fig. 5(b)). It shows that the bush has a crushed zone and a torsional tearing around the circumference of the pin. Rust is also seen on the sample due to the migration of water into the connector bore as the bushings failed [4]. From observation, it was found that the life of rubber bush is dependent on the stresses during filling process, subjected to external load due to track tension. It is also possibly due to the shear load resulting from the relative movement of the blocks and the temperature rise due to the hysteresis of these loads. In this case, it was possibly observed that the rubber bush was subjected to hysteresis friction that is caused by the energy dissipation due to internal material damping during the deformation process [1,14]. The deformed part occurs during the sliding of a rubber element across the rough surface.

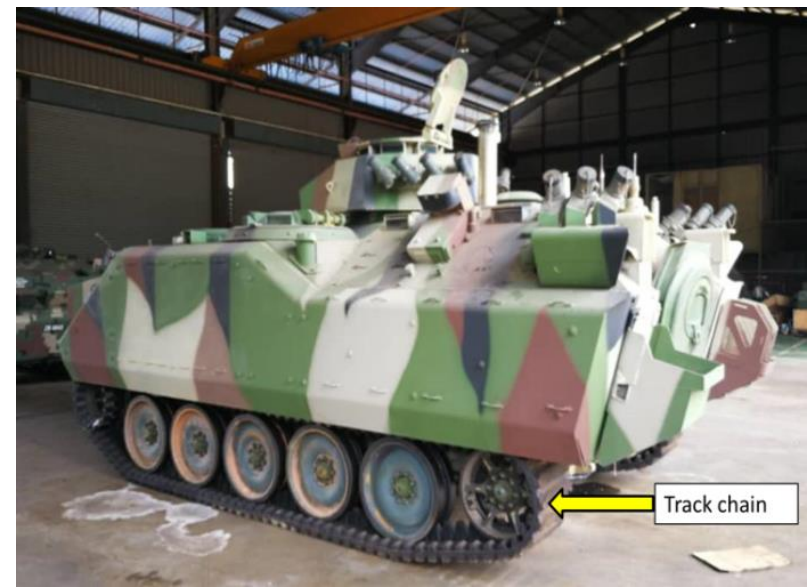

Fig. 2. Track chain ADNAN- Malaysian Armoured Vehicle

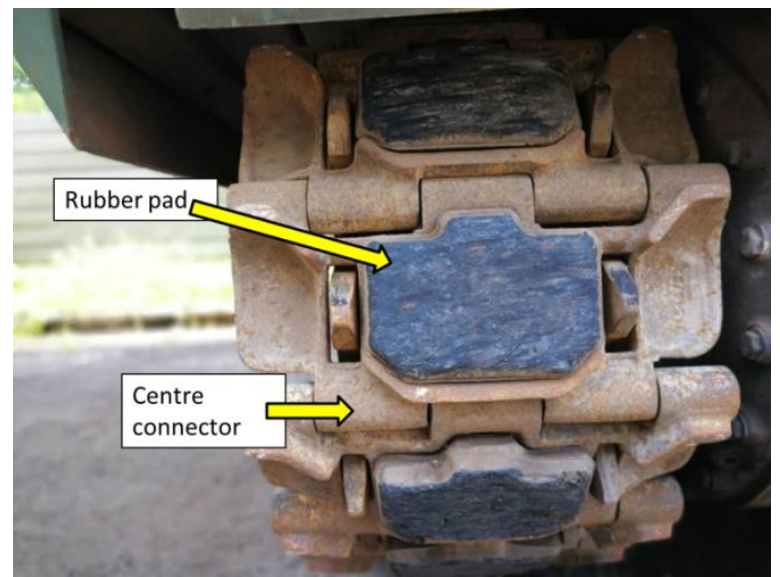

Fig. 3. Track chain with rubber pads ADNAN Malaysian Armoured Vehicle

As reported by Al-Assi and Kassem [1] that rubber generates three different forms of friction which are adhesion, deformation and wear. 
They also stated that the bulk deformation due to hysteresis causes energy losses as rubber slides over the rough surface. In this rubber bush case, it can be said that these energy losses are caused by the hysteretic losses in the rubber material due to loading and unloading.

During the insertion process of bushes into the track block, they elongate in the axial direction till two adjacent bushes get in touch with each other. As the insertion applied and since the rubber behaves as an incompressible material, this process continued until the surface of the rubber bush are in contact with the surface of steel connector and pin side wall respectively as shown in Fig. 5.

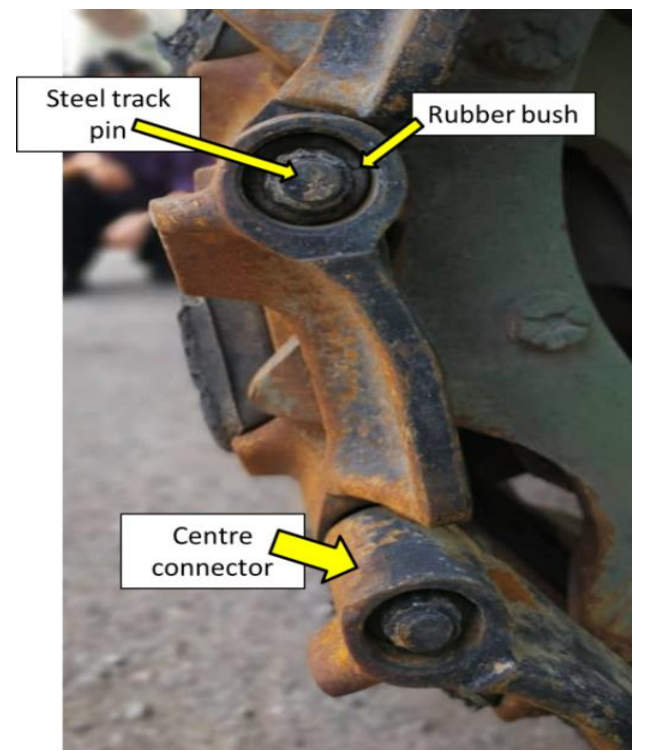

Fig. 4. Track pin ADNAN - Malaysian Armoured Vehicle

As depicted in Fig. 6, the proposed rubber bush wear failure mechanism between the outer surface of the rubber and inner bore of the block surface is identified. The proposed mechanism is divided into three stages which are stage I, II and III. According to the stage I, the inside surface of the rubber bush is in contact with the rigid steel pin and connector side wall and it can be said that the displacement of both surface area are restrained. As proposed in stage I, it shows that both side walls which is in contact with the rubber bush shows a smooth counter face surface. This possibly because of the inner layer of the rubber bush is rigidly fixed. Although it is fixed, some problems could occur and one possible deformation is distortion.

During the insertion of rubber bush, when rigidity becomes an important factor to make sure the rubber bush is fixed, the rubber surface could possibly distort. This makes the outer face of the bush is allowed to slide. As indicated in Stage II, where both fixed and rigid steel connector and pin side wall are in contact with each other, mainly at the area between the rubber and the counter surface, friction could possibly be the cause of the failure. Friction is one of the failure mechanism which is due to two physical phenomena which are (i) adhesion between the surfaces and (ii) is hysteresis loss in rubber [13]. In this case, as the rubber bush slides repeatedly on the side wall counter surface which is rigid compared to rubber, and through time the surface of the steel could deform the rubber surface. It is getting worst if both counter surface of the connector bore and pin were coated with rust as indicated in Fig. 5(b). The rusted area was found on the inner and outer pin surface due to uniform corrosion. As well known, the rust has a rough corroded surface and this would become one of the factors that could damage and deteriorate the rubber surface. When the counter surface of rubber bush is repeatedly deformed, this could leads to energy loss due to the internal friction or also known as hysteresis of the rubber. As consequences, the energy transformed into the heat and continuously supplemented if the sliding speed is intended to be constant [1].

In Stage II as shown in Fig. 5, as the rubber surface slides repeatedly, instead of friction, abrasion could also be one of the effects that worn the rubber bush surface [22]. In this case, abrasive wear can be defined as the removal of material due to penetration of hard particles or surface asperities of the harder steel surface into the softer surface during solid sliding contact [23]. As the sliding force continues, the abrasion and friction caused the removal of rubber particles filled the space area between the spin and inner connector bore surfaces. The rubber particles which were chipped by abrasive wear will act as the stress concentrator factor that may end in a great number of surface damage. Prolonged cyclic stresses of loading and unloading during rubber bush insertion together with sliding and rolling of rubber particles caused the shear and fatigue stresses to occur as indicated in Stage III. Thus, would leads to the deterioration of rubber bush.

Instead of insertion of rubber bush process, the other aspects that need to take into account is the deformation that occur resulting from plain sliding of bushings and pins during service and for instance, when the rubber bush worn and torn due to the rubber deformation as indicated in Stage III (Fig. 6). The illustration of point enlargement of Stage III is depicted in Fig. 7. As well known, armour tank is categorized under heavy machinery that operates in various loads and speeds. At high loads and low speeds, the pins and bushings operate in the regime of boundary lubrication. In this case, when the rubber bush deteriorated, the counter surface of steel pin and connector bore side wall were in rigid contact. At this particular case, the contact stresses were developed due to the connection movement between pins and bushings or also with side wall of the connector bore. This movement allows the rotation of the pin and sliding movement of the bushing which is in contact with internal side wall of connector bore. It is possible to suggest that under such condition, where the deterioration of rubber bush was significant and lack of lubrication between the contacts of similar metals, this condition is prone to the galling failure [3].

Galling is one type of abrasive wear that caused by adhesion between sliding surfaces. This type of wear failure is caused by a combination of friction and adhesion between the metal surfaces, followed by slipping and tearing of crystal structure beneath the surface. According to the Fig. 7, it is possible to note that the major reason for the loss of oil or lubrication in the pin and bushing is the wear of rubber or any other seal type. 
As the rubber bush or seal damaged and deteriorated by abrasives the seizure contact between both metal side walls caused a press-fit condition. The rubber particles or wear debris was found to decrease the clearance between both side walls.
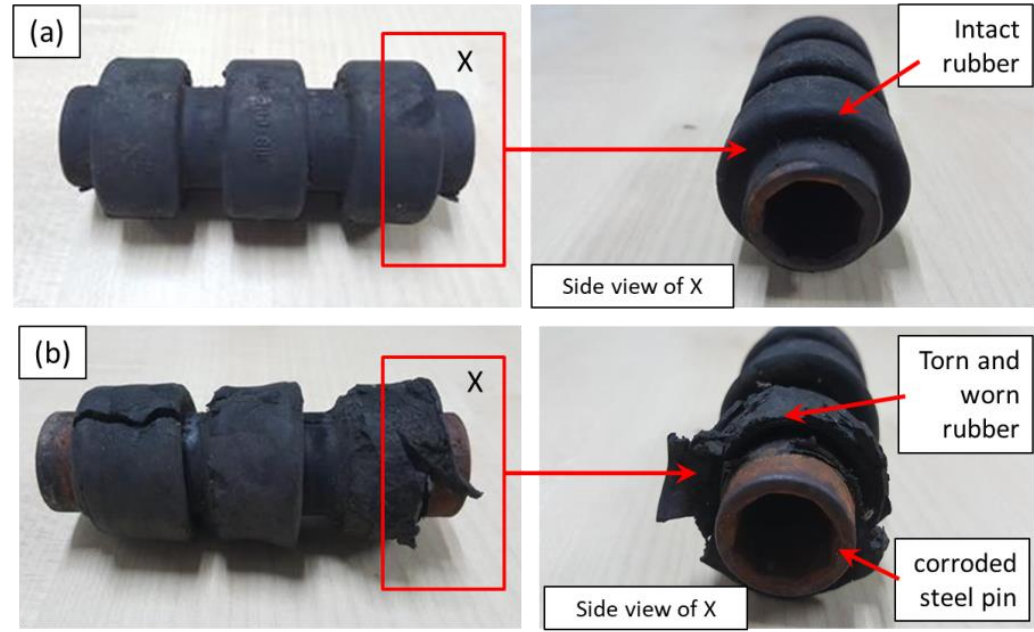

Fig. 5. Rubber bushing failure, (a) intact rubber,and (b) torn and worn rubber
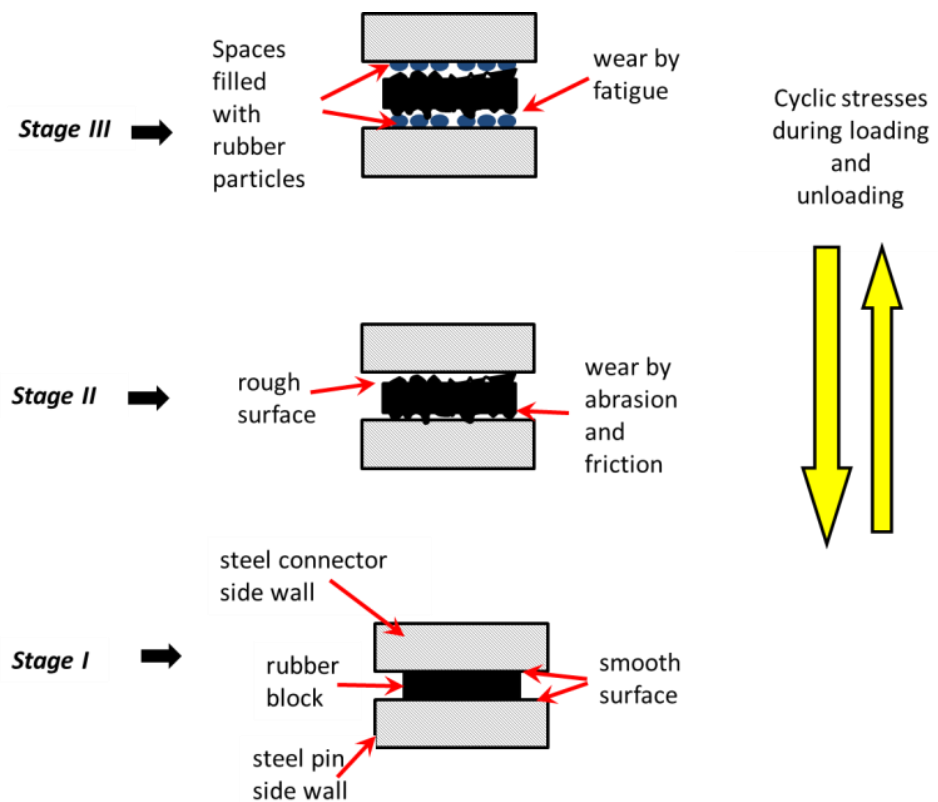

Fig. 6.Illustration of rubber bush wear failure mechanism

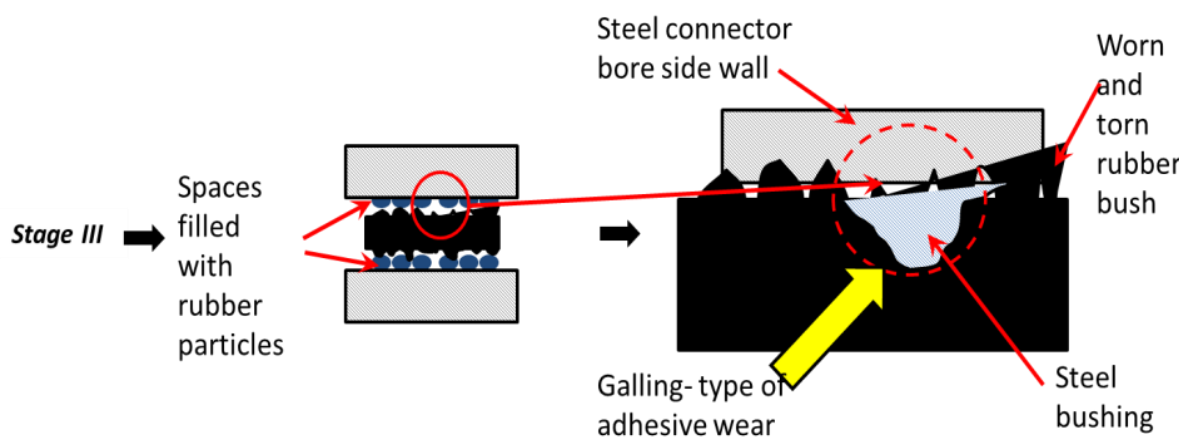

Fig. 7. Illustration of point enlargement of galling wear mechanism of steel connector and bushing side wall

Thus, eventually creates high contact stresses and as the cyclic stresses continues, it's finally creates wear damaged and susceptible for crack to initiate.
Published By: 


\section{CONCLUSION}

From the case study, it is possible to propose rubber bush wear failure mechanism between the outer surface of the rubber and inner bore of the block surface. The proposed mechanism is divided into three stages which are stage I, II and III. In stage I, both side walls which is in contact with the rubber bush shows a smooth counter face surface.

This possibly because of the inner layer of the rubber bush is rigidly fixed. In Stage II, where both fixed and rigid steel connector and pin side wall are in contact with each other, mainly at the area between the rubber and the counter surface, friction could possibly be the cause of the failure. Prolonged cyclic stresses of loading and unloading during rubber bush insertion together with sliding and rolling of rubber particles caused the shear and fatigue stresses to occur as indicated in Stage III. Thus, would leads to the deterioration of rubber bush and this condition is prone to the galling failure.

\section{ACKNOWLEDGMENT}

We gratefully thank the 'RejimenRenjerDirajaMekanize', located at KemBatu 5, Mentakab Pahang, and The Science \& Technology Research Institute ForDefence (STRIDE), Kajang Selangor, for their cooperation in this research project with us from University of Kuala Lumpur Malaysia France Institute (UNIKL MFI).

\section{REFERENCES}

1. Al-Assi, M., \&Kassem, E. (2017). Evaluation of adhesion and hysteresis friction of rubber-pavement system. Applied Sciences, 7(1029), 1-13.

2. Bennink, C. (2010). Common failure points for rubber track. For Construction Pros.com.

3. Farzaneh, N. (2002). Failure analysis and design of a heavily loaded pin joint. (Master), Massachusetts Institute of Technology, Massachusetts.

4. Gruenberg, S., Bradley, S., Gentner, S., \&Ostberg, D. (2014). New technologies for military track bushing accelerated testing and evaluation. NDIA Ground Vehicle Systems Engineering and Technology, 1-6.

5. Hornback, P. (1998). The wheel versus track dilemma. Armor, 33-34.

6. Karafiath, L. L. (1980). Analytical model for the turning of tracked vehicles in soft soils (pp. 1-62). Bethpage, New York: Research Department Grumman Aerospace Corporation.

7. Kulkarni, N. M. (2016). Design optimisation of tank track pad meta-material using the unit cell synthesis method. (Master of Science), Clemson University, United States of America.

8. Lasuer, D. R., Santor, S. D., Cornell, R. H., \&Patt, J. (1983). Field evaluation of tank track pad failures (pp. 1-40). Livermore, California: Lawrence Livermore National Laboratory.

9. Lessem, A. S., \& Murphy, Jr. N. R. (1972). Studies of the dynamics of tracked vehicles (pp. 1-47). Vicksburg, Mississippi: U. S. Army Engineer Waterways Experiment Station

10. Madhu, V., \& Bhat, T. B. (2011). Armour protection and affordable protection for futuristic combat vehicle. Defence Science Journal, 61(4), 394-402.

11. Mars, W. V., Castanier, M., Ostberg, D., \& Bradford, W. (2017). Digital twin for tank track elastomers: Predicting self-heating and durability. NDIA Ground Vehicle Systems Engineering and Technology, 1-10.

12. McKenna, G. B. (1987). Durability testing of tank track rubber compunds under cyclic loading (pp. 1-58). Gaithersburg, Maryland: Polymers Division, National Bureau of Standards.

13. Palfi, L., \&VAradi, K. (2009). Theorethical prediction of hysteretic rubber friction in ball on plate configuration by finite element method. Express Polymer Letters, 3(11), 713-723.

14. Palfi, L., \&Varadi, K. (2010). Hysteretic friction of rubber in tribological tests. PeriodicaPolytechnica, 54(2), 63-69.

15. Radighieri, G. A. (2002). Galling failures in pin joints. (Master), Massachusetts Institute of Technology, Massachusetts.

16. Ramamurthy, N. V., Vinayagam, B. K., \&Roopchand, J. (2018). Ergonomic level improving of armoured fighting vehicle crew. Defence Science Journal, 68(7), 33-45.
17. Richard, M. G. (2008). Rubber tracks make military vehicles more efficient, durable, and quieter.

18. Sridhar, S., Prasad, N. S., \&Seetharamu, K. N. (1997). Some studies on life of track pin rubber bushes. Defence Science Journal, 47(2), 251-257.

19. Thavamani, P., Bhowmick, A. K., \&Khastgir, D. (1993). Effect of ageing on strength and wear of tank track pad compounds. Wear, 170(1), 25-32.

20. Touchet, P., Rodriguez, G., Gatza, P. E., Butler, D. P., Crawford, D. M., Teets, A. R., Flanagan, D. P. (1992). United States of America Patent No. United States Patent.

21. Valpolini, P. (2013). Infantry fighting veihcles and armoured personnel carriers. Armada Compendium IFV \& APC, 1-40.

22. Verma, R., Tiwari, S., \&Gehlot, V. (2014). An investigation of abrasive wear in rubber material. International Journal of Advanced Mechanical Engineering, 4(6), 681-686.

23. Yekrangi, A., Afrasiabi, M., Langari, A., \&Hafshejani, M. K. (2014). Investigation of abrasion and morphology of rubber/nano titanium oxide composites. ARPN Journal of Engineering and Applied Sciences, 9(4), 580-586.

\section{AUTHORS PROFILE}

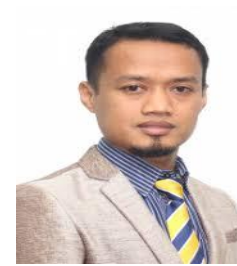

Muhamad Hellmy Hussin, is a lecturer in University of Kuala Lumpur Malaysia France Institute (UNIKL MFI) located at Bandar BaruBangi, Selangor for fourteen years. His expertise is in Innovation and Engineering Design, and also in Corrosion and Failure Analysis. He did his Bac. (Hons.) in Industrial Production Management at the University Nice Sophie Antipolis (UNSA), France, and then pursued his Master Degree in Innovation and Engineering Design at University of Putra Malaysia (UPM) Serdang, Selangor.Over the last eight years he becomes involved in welding and joining research works. And since then he has continued his research and involved in Corrosion and Failure Analysis research areas, Corrosion and failure analysis works. Now, he pursue his PhD in (Mechanical), focusing on High Temperature Corrosion in Hot Gases Environment. He has published articles and journals mainly in Welding and Joining, Corrosion degradation and Failure Analysis research works.

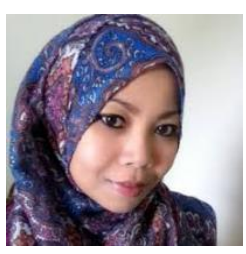

Dr. NurAzida CheLah, is a senior lecturer at the University of Kuala Lumpur Malaysia France Institute (UNIKL MFI), Bandar BaruBangi, Selangor. She did her Bac (Hons) in Materials Science and then pursued her Master degree in Mechanical Engineering majoring in Fatigue failure Assessment on welded joint at University of Putra Malaysia (UPM) Serdang, Selangor. Her PhD focusing on High Temperature Corrosion Study on Aluminium Welded Joint at The National University of Malaysia (UKM), Bangi, Selangor. And since 2007 she started writing an articles and journals mostly on Fatigue Assessment Analysis, Welding and Joining, Corrosion degradation and Failure Analysis Studies.

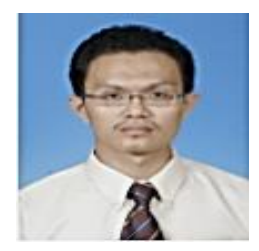

Ir. Dr. Shamsul Akmar Ab Aziz born in 1979, currently working with The Science \& Technology Research Institute For Defence (STRIDE), located at Kajang, Selangor, Malaysia. He did his $\mathrm{PhD}$ in Mechanics of Materials Engineering at University of Malaysia (UKM) in 2016. 